\title{
20. Evaluation of Ventriculo-Pleural Shunt for Hydrocephalus
}

\author{
Masashichi KaWAno, Jiro Moroki and Hirohisa ONo \\ Department of Surgery, Nagasaki University School of Medicine
}

Ventriculo-pleural shunt was tried for hydrocephalus by Heile in 1918, but never became popular until Ransohoff called attension to this technic. Main hazard of this operation is intrapleural adhesion and subsequent obstruction of the tube. Another discouraging complication is dyspnea due to either over-drainage or poor absorption through pleura.

To avoid over-drainage we used the silicone tube of Pudenz type which has a pressure control device; To avoid adhesion and migration of the tube we prefered anterior route to the conventional posterior route; the lower tube was induced into the pleural cavity through the anterior intercostal space intstead of posterior intercostal space.

Using this technic (Kawano's method) ventriculo-pleural shunt was tried on 23 hydrocephalic patients with or without brain tumor, and the result was compared with other technic which was performed by the same operator, i.e., ventriculo-auricular shunt 15, Torkildsen's procedure 6, and ventriculo-peritoneal shunt 2 .

There was no operative death due to this operation. There is no danger of serious complications of ventriculo-auricular shunt, thrombosis of the vena cava, embolism, septicemia or cardiac arrest in this operation. Ten patients needed revision of the shunt because of obstruction of the tube. After various intervals of time, eleven patients developed poor absorption of the fluid in the pleura and the lower tube was introduced into the atrium through the jugular vein without changing the upper tube. Five patients died of brain tumors and one because of serious meningomyelocele.

One of the early case of ventriculo-auricular shunt died of cardiac arrest, but other 14 cases did well.

Biggest advantage of ventriculo-pleural shunt is that one can operate immediately after ventricular air study without fear of air embolism. Besides, the technic is simple and safe. It should be tried on any type of hydrocephalus of different etiology unless there exists pulmonary complication. 